\title{
Instrumentalization of Eating Improves Weight Loss Maintenance in Obesity
}

\author{
Bodil Just Christensen ${ }^{a}$ Eva Winning Iepsen ${ }^{b}$ Julie Lundgren ${ }^{b}$ \\ Lotte Holm $^{a}$ Sten Madsbad ${ }^{c}$ Jens Juul Holst ${ }^{b}$ Signe Sørensen Torekov ${ }^{b}$ \\ a Institute of Food and Resource Economics, University of Copenhagen, Copenhagen, \\ Denmark; ${ }^{b}$ Department of Biomedical Sciences, Faculty of Health and Medical Sciences, \\ University of Copenhagen and the NNF Center for Basic Metabolic Research, Copenhagen, \\ Denmark; ${ }^{c}$ Department of Endocrinology, Hvidovre University Hospital, Hvidovre, Denmark
}

\section{Keywords}

Obesity · Body weight maintenance · Psychosocial aspects · Interviews · Quantification · Qualitative research

\begin{abstract}
Aim: The purpose of this study was to identify psychosocial determinants for maintaining weight loss. Methods: 42 obese individuals who achieved a $12 \%$ weight loss before entering a 52-week weight maintenance program were interviewed qualitatively. Psychosocial factors related to weight loss maintenance were identified in two contrasting groups: weight reducers and weight regainers. Groups were defined by health-relevant weight maintenance (additional weight loss $>3 \%$ at week $52, n=9$ versus weight gain $>3 \%$, at week $52, n=20$ ). $\boldsymbol{R e}$ sults: Weight reducers reported structured meal patterns $(p=0.008)$, no comfort eating $(p=$ $0.016)$ and less psychosocial stress $(p=0.04)$ compared to weight regainers. The ability to instrumentalize eating behavior emerged as an important factor $(p=0.007)$. Nutritional knowledge, motivation or exercise level did not differ between groups $(p>0.05)$. Conclusions: Successful weight loss maintenance was associated with an interplay between behavioral, affective and contextual changes. 'Instrumentalization of eating behavior' seems to be an important element in long-term weight maintenance.

(c) 2017 The Author(s)

Published by S. Karger GmbH, Freiburg
\end{abstract}

Bodil J. Christensen and Eva W. Iepsen contributed equally to the manuscript. 
Christensen et al.: Instrumentalization of Eating Improves Weight Loss Maintenance in Obesity

\section{Introduction}

Obesity is related to increased morbidity and mortality [1, 2], decreased quality of life and psychological stress [3, 4]. Maintaining weight loss is a major public health concern Lowcalorie diets are efficient in obtaining rapid and large weight reductions [5] but the lost weight is usually regained $[6,7]$ unless targeted weight loss maintenance strategies are initiated [8]. Current clinical weight loss intervention programs often fail to address weight loss maintenance, resulting in weight regain and an unhealthy pattern of weight cycling [9].

Previous studies and clinical experience indicate that relapse into obesity after weight loss is attributable to several concurrent factors [8]. It is suggested that biological, behavioral, affective and contextual factors interact in complex ways and may lead to disordered eating behavior, excessive energy intake, and weight regain [10].

Behavioral factors, such as dietary intake and meal patterns, and psychological factors, such as motivation and self-efficacy, have been identified as predictors of weight development [8]. Notably, eating behavior is deemed a crucial element in successful weight maintenance. Often this factor is evaluated by assessing eating restraint, disinhibition and hunger. Control over eating is a common feature of several psychometric measures of weight maintenance predictors [11] such as the Three Factor Eating Questionnaire (TFEQ) [12]. Concepts such as restraint, disinhibition, self-efficacy [13], and locus of control [14] build on the assumption that a reduction in caloric intake requires self-control and the ability to make careful choices. In addition to control, choice is thus seen as central as patients have to exercise control in daily decisions on what foods to eat. However, some studies argue that food choices generate challenges. Thus, 'the freedom of choice' may impose a strenuous sense of responsibility requiring continuous efforts to adopt restrictive dietary routines $[15,16]$. It is argued that, paradoxically, the removal of choice may improve and help re-establish self-control as fewer choices are experienced as a release [11]. Further, the eating strategies patients adopt after weight loss vary [17] suggesting that successful weight maintenance is individual and complex. On this basis, we suggest that a shift in focus from cognitive restraint and control and calorie reduction to patients' context-centered strategies and actual practices may elicit new insights into successful weight loss maintenance. We hypothesize that long-term outcomes depend on interplays between factors, notably affective and contextual factors, rather than on single factors such as control over eating or physical activity. Therefore, we investigated which factors facilitate or hamper long-term weight loss in 42 obese individuals who underwent a diet-induced weight loss of $12 \%$ followed by 52 weeks weight loss maintenance period [18]. An exploratory design was adopted in order to move past existing frameworks of explanation. Semi-structured interviews were chosen over standard psychometric quantitative measure to provide novel insights. In quantitative questionnaires and scales, items and factors are defined a priori, whereas in open-ended interviews factors are unknown. Thus, there is the added complexity of first determining what the factors are, and then providing a much richer, more detailed, and perhaps more accurate representation [19]. To secure validity of the analysis, interview data were subjected to verbal data analysis and statistical analysis.

\section{Subjects and Methods}

Weight Maintenance Study

42 participants achieved a weight loss of $12 \%$ by adhering to a low-calorie powder diet consisting of $810 \mathrm{kcal} /$ day $(3,402 \mathrm{~kJ} /$ day) for 8 weeks. Products were provided by Cambridge Diet (Cambridge Weight Plan, Corby, UK) [20], and the participants received support by weekly meetings with dieticians. Participants were subsequently randomized into two groups, one receiving the glucagon-like-peptide 1 receptor agonist (GLP-1 RA), liraglutide, $1.2 \mathrm{mg} /$ day for 52 weeks and a control group. 
Participants were instructed in restricted calorie intake by calculation of their estimated daily energy need subtracted by $600 \mathrm{kcal}$ and were encouraged to follow nutritional recommendations. Both groups maintained their weight loss with no significant difference between the groups at 12 months [18].

\section{Interview Study}

Semi-structured qualitative interviews were conducted with all 42 participants using a thematic openended interview guide, which invited interviewees to express themselves freely and to describe their behaviors, experiences, and concerns from their own perspective [21]. The interviews covered five thematic areas, which have been identified as relevant in previous studies [8, 22, 23]: personal motivation; weight biography; former and new eating habits; physical activity routines; support, social network and barriers to lifestyle changes. Participants were interviewed at the research clinic in a separate room. The interviews were conducted at the end of the trial (week 52) and had an average length ( \pm SEM) of $63 \pm 5$ min.

\section{Weight Trajectories}

Participants were grouped according to their body weight change after the 52-week long weight maintenance period. As a weight loss exceeding $3 \%$ is considered beneficial for cardiovascular as well as metabolic health [24], this value was used as a cut-off value for successful weight loss maintenance. Two groups were created: i) weight reducers with a mean weight loss from baseline to week 52 of $-3 \%$ or above, and ii) weight regainers with a mean weight gain above $+3 \%$.

\section{Qualitative Data}

Professional verbatim transcriptions were made of the recorded interviews. Transcripts were anonymized and imported into the NVivo 9 software package. Salient themes and concepts were identified using standard qualitative content analyses [25]. Thus, a hypothesis-free inductive approach was used, which secures grounding in the data of identified analytical themes and the inferences drawn from them. Transcripts were coded and read several times to refine the initial coding and allow new themes to emerge. When consistency was achieved, a condensation of themes and concepts into psychosocial parameters was performed based on inference and interpretation [26]. A final coding framework was developed and applied iteratively to all transcripts. The interview coding was performed with weight loss and randomization blinded in order to avoid bias.

Verbal data analysis [19] was used in order to re-code the identified psychosocial parameters into numerical variables denominated 1, 2 and 3 indicating low, medium and high level of the parameter in question, respectively. The quantification allowed to depict the data statistically and to perform analyses in order to confirm or disconfirm reliable differences [27]. To validate that participants were assigned the right score, the definitions and ratings of factors shown in table 1 were specified by first determining the features of each of the factors, which were then assigned three graduated ratings based on the full data set. For example, for 'meal pattern' participants' number of meals per day varied from one to six, and the ratings were assigned accordingly: i) 5-6 meals a day, ii) 3-4 meals, and iii) 2 meals or less. The interviews were then re-examined to make sure that evidence for the score was articulated. Univariate general linear models were then performed comparing the group-depending effects (weight reducers and regainers) on each of the psychosocial parameters identified from the interviews. Independent T-tests were performed to investigate whether liraglutide was an explaining factor in the observed differences between the weight loss groups. All analyses were performed with treatment (liraglutide or not), sex, and age as co-variates (SPSS Statistics, version 22; IBM Corporation, Armonk, New York, NY, USA).

\section{Data Saturation in Qualitative Analysis}

To ensure that possible explanatory factors and their variation were identified, the following calculation for data saturation was made based on previous studies $[28,29]$. To obtain a significant number of individuals in both the weight reducer group and the weight regainer group, the minimum sample size was set to $\mathrm{n}=40$, as research has shown that $20 \%$ of overweight individuals are successful at long-term weight loss when defined as losing and maintaining at least $10 \%$ of initial body weight for at least 1 year [30]. With a sample size of 42 , we expected that 9 individuals would be successful. Previous qualitative studies and textbook literature establish that data saturation for meta-themes is secured at $n=6[28,29]$. 
Christensen et al.: Instrumentalization of Eating Improves Weight Loss Maintenance in Obesity

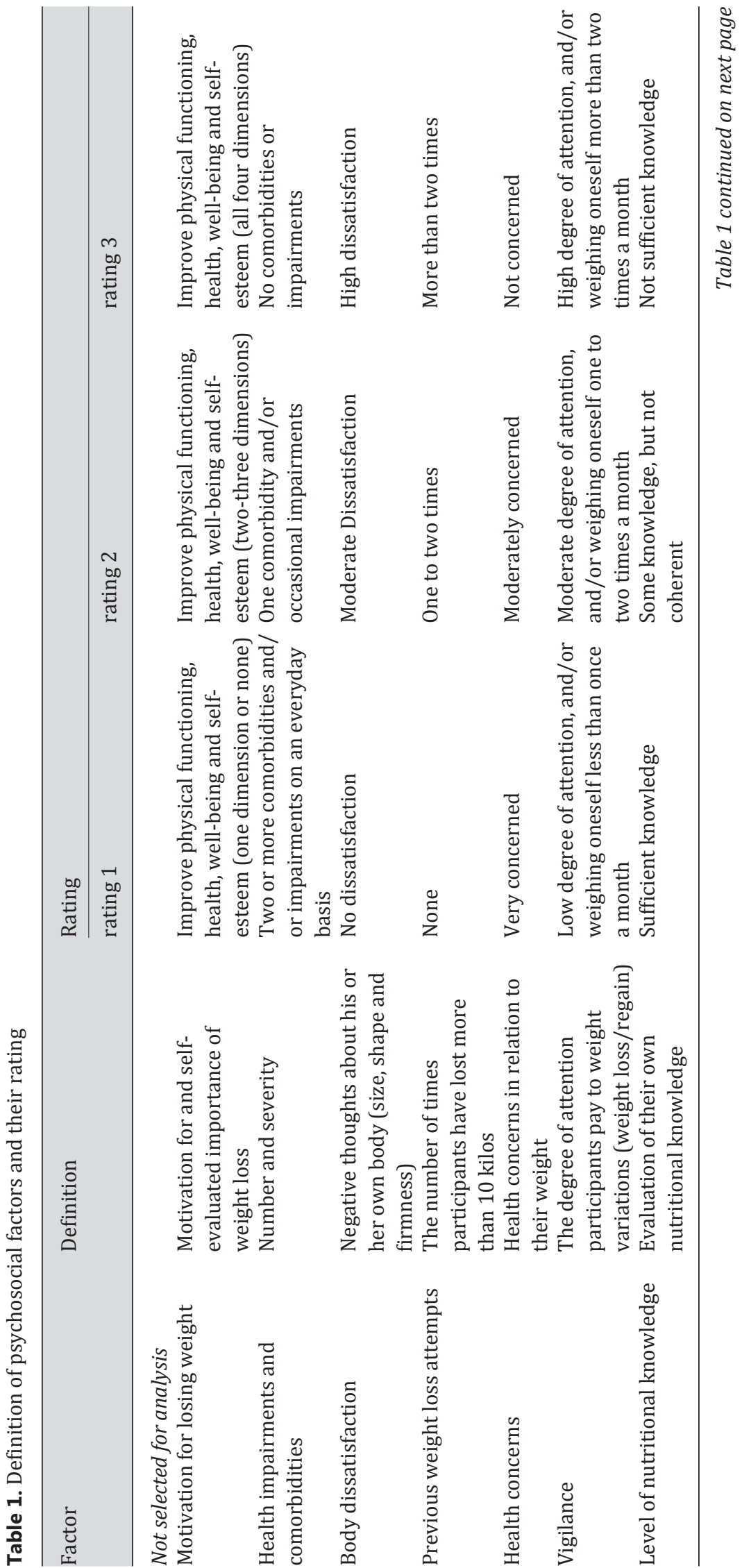


Christensen et al.: Instrumentalization of Eating Improves Weight Loss Maintenance in Obesity

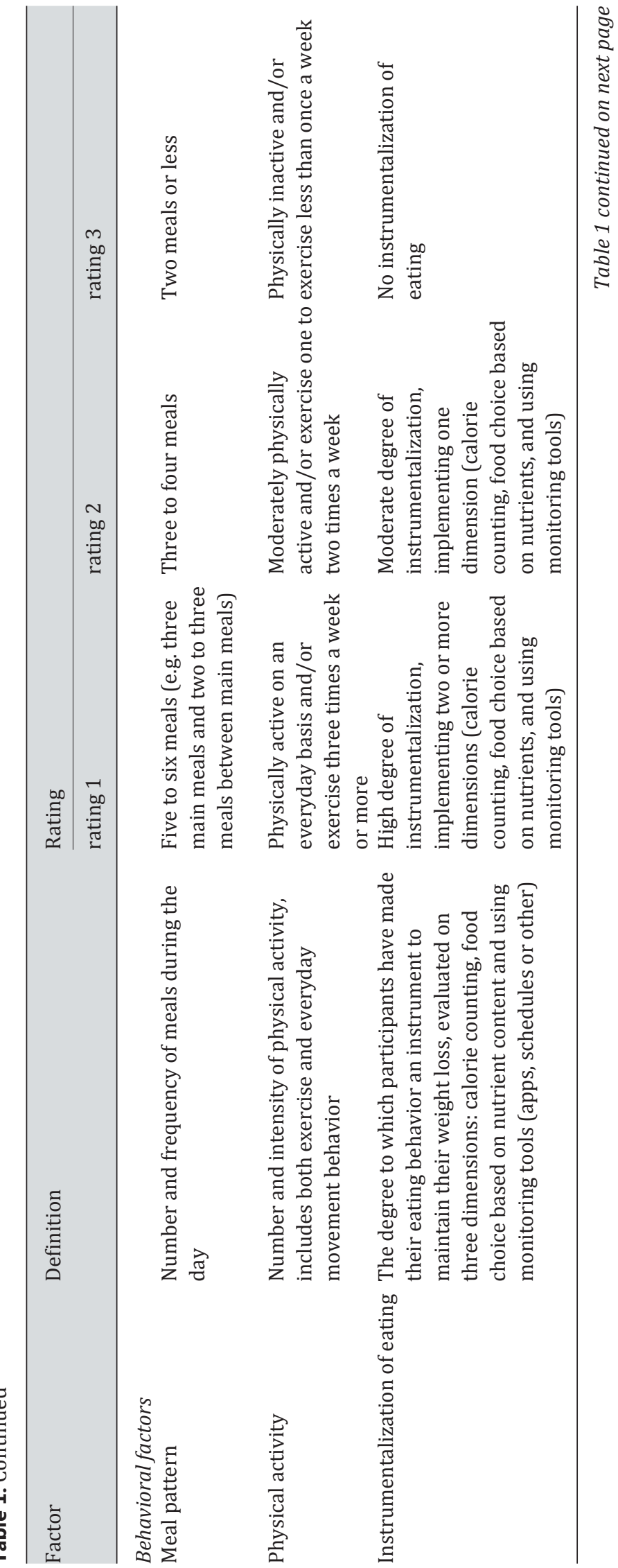


Christensen et al.: Instrumentalization of Eating Improves Weight Loss Maintenance in Obesity

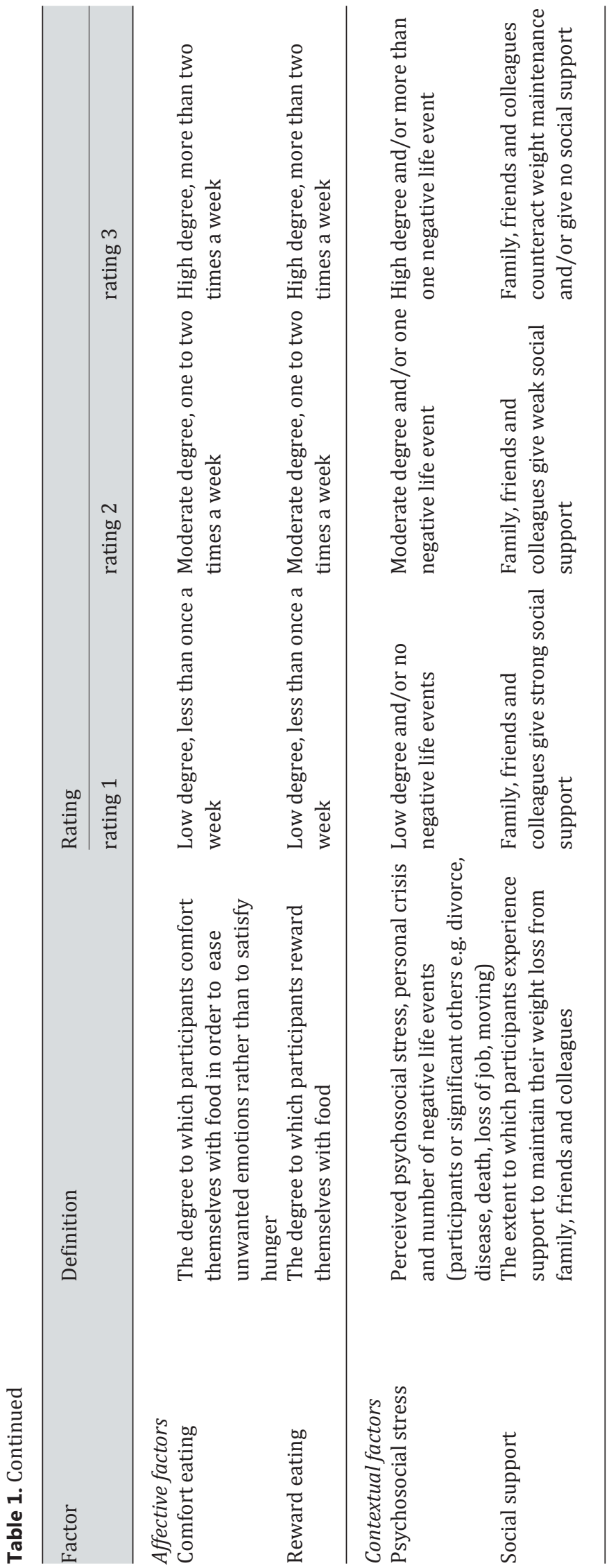


Fig. 1. Weight trajectories for weight reducers (black squares) and weight regainers (open circles) based on weight difference in percent from baseline to week 52 . Weight reducers $n=9$, weight regainers $n=20$.

Christensen et al.: Instrumentalization of Eating Improves Weight Loss Maintenance in Obesity

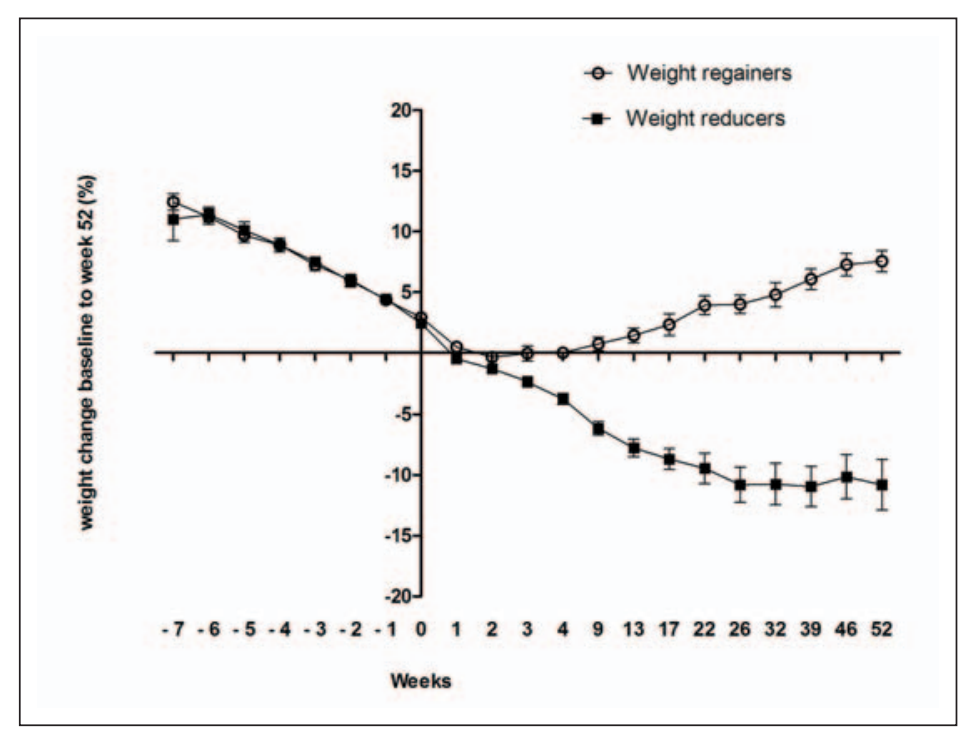

\section{Ethical Issues}

The clinical trial was approved by the ethical committee in Copenhagen (reference number: H-4-2010134) and was performed in accordance with the Helsinki Declaration II. Participation in the investigation was voluntary, and the individuals could at any time retract their consent to participate. ClinicalTrials.gov Identifier: NCT02094183.

\section{Results}

Nine weight reducers and 20 weight regainers were identified based on a weight loss from baseline to week 52 of above $-3.0 \%$ and a weight gain from baseline to week 52 of above $+3.0 \%$, respectively (fig. 1 ).

\section{Psychosocial Parameters Characterizing Weight Reducers and Regainers}

The explorative investigation of the role of control and choice in eating strategies revealed that participants had very different strategies for structuring and managing their food choice. Weight reducers generally had a high degree of structure; they adhered to rules and chose their food based on nutritional content and less on personal preferences or palatability. In contrast, weight regainers failed to implement the same rules and were guided by palatability and reward when choosing food. The content analysis of interview data identified the following factors as relevant for weight loss maintenance: motivation for losing weight, health impairments and comorbidities, body dissatisfaction, previous weight loss attempts, health concerns, vigilance, level of nutritional knowledge, degree of structured meal pattern, physical activity, comfort eating, reward eating, psychosocial stress, social support, and a new factor which we label 'instrumentalization of eating' (table 1). However, the subsequent analysis showed no differences between weight reducers and regainers with respect to motivation for losing weight, health impairments and comorbidities, body dissatisfaction, previous weight loss attempts, health concerns, vigilance, and level of nutritional knowledge; thus these factors were not selected for further analysis. All participants reported to be highly motivated to lose weight, and the majority (86\%) already felt they had the nutritional knowledge they needed. 
Christensen et al.: Instrumentalization of Eating Improves Weight Loss Maintenance in Obesity

Table 2. Citation table. Verbatim quotes illustrating how weight reducers and weight regainers differed with respect to behavioral, affective and contextual factors

\begin{tabular}{|c|c|c|}
\hline & Weight reducers & Weight regainers \\
\hline Meal pattern & $\begin{array}{l}\text { I have a maximum limit of } 2.5 \mathrm{~h} \\
\text { between my meals. } \\
\text { Back then I often forgot to eat, } \\
\text { but now I eat } 5 \text { meals a day. } \\
\text { I eat smaller portions, but more often. }\end{array}$ & $\begin{array}{l}\text { If I for instance eat something with sugar in the afternoon, then } \\
\text { I might not be hungry in the evening, and then I might not have } \\
\text { supper. } \\
\text { I forget to eat between meals. } \\
\text { I don't eat much during the day, and I never have breakfast. }\end{array}$ \\
\hline $\begin{array}{l}\text { Level of physical } \\
\text { activity }\end{array}$ & $\begin{array}{l}\text { I am much more physically active than } \\
\text { ever before, also at work. } \\
\text { I exercise four times a week. } \\
\text { I have become addicted to exercise. } \\
\text { It is my abuse. It really is, if more } \\
\text { than three to four days pass, I get } \\
\text { withdrawal symptoms. }\end{array}$ & $\begin{array}{l}\text { I'm not the kind of person who sits on a bicycle in the gym; I } \\
\text { just don't want to. I think it's the most boring thing in the world. } \\
\text { The worst thing is that I have not been able to exercise. } \\
\text { More than } 10 \text { years ago I was in an accident. I badly hurt my } \\
\text { joints. Now I have osteoarthritis in my knees and back. I am in } \\
\text { pain } 24 / 7 \text {. }\end{array}$ \\
\hline $\begin{array}{l}\text { Instrumental- } \\
\text { ization }\end{array}$ & $\begin{array}{l}\text { I have a rule that each main meal must } \\
\text { not contain more than } 500 \text { calories. } \\
\text { Protein, fat and fiber are something } \\
\text { that I keep an eye on. I have never } \\
\text { done that before. } \\
\text { I eat much less carbohydrates and } \\
\text { much more proteins. }\end{array}$ & $\begin{array}{l}\text { I know that if I eat low fat meat and especially fish, I lose a lot of } \\
\text { weight. And I really like it. But I just can't seem to get it } \\
\text { implemented. } \\
\text { At the moment, I only eat the kind of food that I like. But I guess } \\
\text { it is mostly sweet and fat stuff. } \\
\text { The food diary system does not work for me. I start making my } \\
\text { own rules: 'oh, I can eat a little more now I will just eat less } \\
\text { tomorrow'. But then I also eat more the day after. }\end{array}$ \\
\hline Comfort eating & $\begin{array}{l}\text { A small piece of cake tastes the same } \\
\text { good as a big piece. } \\
\text { I can buy the chocolate today, } \\
\text { but I will not eat it until Saturday. } \\
\text { If I am at a birthday party, I will } \\
\text { have a piece of cake. You should not } \\
\text { be too hard on yourself. }\end{array}$ & $\begin{array}{l}\text { Food makes me happy. I feel calm when I eat food. } \\
\text { I do not only comfort-eat - I also eat when I am happy. } \\
\text { To resist a craving is like trying not to breath. At a certain point } \\
\text { you have to surrender. }\end{array}$ \\
\hline Reward eating & $\begin{array}{l}\text { Now that I have made it all through } \\
\text { the day, I feel that I have deserved } \\
\text { something, like a small award. But it is } \\
\text { not as much as it used to be. } \\
\text { Monday to Thursday I eat } 1,200 \mathrm{kcal} \text {, } \\
\text { and Friday, Saturday and Sunday I eat } \\
\text { what I want but still reasonable - and } \\
\text { without feeling guilty . } \\
\text { Candy is a treat for me, and at } \\
\text { weekends I reward myself for not } \\
\text { eating it the rest of the week. }\end{array}$ & $\begin{array}{l}\text { You think that you have deserved something when you have } \\
\text { had a tough day; you deserve to get something. } \\
\text { If I am tired or have had a hard day at work or have controlled } \\
\text { my food for some time then I feel like I deserve it, then I eat } \\
\text { crisps, and chocolate - sometimes several days in a row. } \\
\text { And then, when things finally settle down and the kids are } \\
\text { asleep, there is still some work waiting to be done. It is obvious } \\
\text { that it requires some kind of stimuli. The additional food } \\
\text { provides the energy for a fully booked life. }\end{array}$ \\
\hline
\end{tabular}


Table 2. Continued

Weight reducers

I really like my job. I have been in the same department for more than ten years.

I have a nice and caring family. The timing has just been right. I had the motivation, and could put the time in.
Weight regainers
Psychosocial stress
My mum was very sick at that time, and I am the one in the family who takes responsibility. I am the one who makes sure that everything works out fine.

I was diagnosed with osteoarthritis and dysplasia of the hip. I qualified as electrician, but I could not work, and I could not trim by jogging. It was a sharp blow that my body was ruined. The past year has been the hardest year ever. People close to me got really bad diagnoses and illnesses, and I changed jobs and had a hard time.
Social support

\author{
My husband have really supported me \\ - and lost $9 \mathrm{~kg}$ during the time I have \\ been on the diet. \\ We've changed our eating habits at \\ home, but my family actually think that \\ the food tastes even better now. \\ My colleagues have followed me and \\ my weight loss. It has been great. They \\ have encouraged me and supported \\ me a lot. Said things like: My God, you \\ have lost so much weight, you look \\ wonderful!
}

My wife buys sweets though I have asked her not to. It is easy for me not to buy it, but if it is in the house I will eat it all. Being out can be very challenging. My family and friends have had some difficulty accepting (my diet). They say things like: 'Come on! Eat it today - wear it tomorrow', or 'go on, have another piece' or 'just have a glass of wine'. I am the father of three boys aged 18, 16 and 12 . They are fond of traditional (fatty) Danish dishes, gravy and potatoes. Then I get trapped: I cook for them and then I of course eat with them.

Seven main factors discriminated weight reducers and regainers: the novel degree of instrumentalization and six factors also identified as important in previous studies $[6,8,10$, 11]: meal pattern, level of physical activity, comfort eating, reward eating, psychosocial stress, and social support. Meal pattern was retained as an individual factor as it was part of the dietary counseling that patients received as part of the intervention. Inspired by Byrne et al. [38], these factors were divided into three categories: behavioral, affective and contextual. Verbatim quotes illustrating how weight reducers and regainers differed with respect to the behavioral, affective, and contextual factors are presented in table 2 .

Table 3 is a score sheet for the seven main factors for each participant. Weight reducers' strategies were characterized by a high degree of instrumentalization, low degrees of comfort eating, reward eating and psychosocial stress, a highly structured meal pattern, and high to moderate degrees of social support, whereas there was no clear pattern for physical activity.

Weight regainers' reports were less uniform: The majority reported a moderately structured meal pattern, poor or moderate degrees of instrumentalization of eating, high and moderate levels of comfort and reward eating, moderate to high degree of psychosocial stress, and moderate to weak social support.

Thus, there were significant differences in the degree to which weight reducers and regainers had a regular meal pattern $(p=0.008)$, had instrumentalized their eating $(p=$ $0.007)$, used comfort eating ( $p=0.016)$, and were subjected to psychosocial stress ( $p=0.04)$. Social support, reward eating, and physical activity routines were not different between the groups ( $p>0.05$ ). Receiving or not receiving $1.2 \mathrm{mg}$ /day liraglutide did not have any significant impact on these parameters $(p>0.05)$. 
Christensen et al.: Instrumentalization of Eating Improves Weight Loss Maintenance in Obesity

Table 3. Score sheet for weight reducers and regainers on factors negatively and positively associated with weight loss

\begin{tabular}{|c|c|c|c|c|c|c|c|c|}
\hline & \multicolumn{3}{|c|}{ Behavioral factors } & \multicolumn{2}{|c|}{ Affective factors } & \multicolumn{2}{|c|}{ Contextual factors } & \multirow[t]{2}{*}{ Sum } \\
\hline & $\begin{array}{l}\text { meal } \\
\text { pattern }\end{array}$ & $\begin{array}{l}\text { physical } \\
\text { activity }\end{array}$ & instrumentalization & $\begin{array}{l}\text { comfort } \\
\text { eating }\end{array}$ & $\begin{array}{l}\text { reward } \\
\text { eating }\end{array}$ & $\begin{array}{l}\text { psychosocial } \\
\text { stress }\end{array}$ & $\begin{array}{l}\text { social } \\
\text { support }\end{array}$ & \\
\hline P value $^{\mathrm{a}}$ & 0.008 & 0.275 & 0.007 & 0.016 & 0.15 & 0.04 & 0.13 & $<0.0001$ \\
\hline \multicolumn{9}{|c|}{ Weight reducers } \\
\hline A1 & 1 & 1 & 1 & 1 & 2 & 1 & 2 & 9 \\
\hline $\mathrm{A} 2$ & 2 & 2 & 1 & 1 & 1 & 1 & 1 & 9 \\
\hline A3 & 1 & 2 & 2 & 1 & 2 & 2 & 2 & 12 \\
\hline $\mathrm{A} 4$ & 1 & 1 & 1 & 1 & 1 & 1 & 1 & 7 \\
\hline A5 & 1 & 2 & 1 & 1 & 1 & 1 & 2 & 9 \\
\hline A6 & 1 & 1 & 1 & 1 & 1 & 1 & 2 & 8 \\
\hline A7 & 1 & 1 & 1 & 2 & 1 & 2 & 2 & 10 \\
\hline A8 & 1 & 3 & 1 & 3 & 1 & 2 & 2 & 13 \\
\hline A9 & 2 & 2 & 2 & 1 & 2 & 1 & 2 & 12 \\
\hline
\end{tabular}

Weight regainers

C1
C2
C4
C5
C6
C7
C8
C9
C10
C11
C12
C13
C14
C15
C16
C17
C18
C19
C20

$\begin{array}{lll}2 & 2 & 2 \\ 2 & 2 & 2 \\ 2 & 2 & 2 \\ 2 & 2 & 3 \\ 1 & 1 & 1 \\ 2 & 3 & 2 \\ 2 & 1 & 1 \\ 2 & 3 & 1 \\ 1 & 3 & 1 \\ 2 & 3 & 2 \\ 2 & 2 & 2 \\ 2 & 2 & 3 \\ 2 & 2 & 3 \\ 1 & 2 & 3 \\ 1 & 3 & 3 \\ 2 & 3 & 3 \\ 2 & 2 & 2 \\ 2 & 1 & 2 \\ 2 & 3 & 3 \\ 2 & 1 & 3\end{array}$

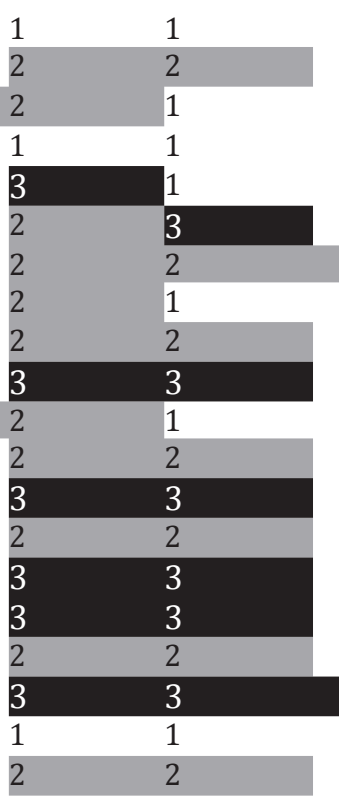

\begin{tabular}{lll}
\hline 2 & 2 & 12 \\
3 & 2 & 15 \\
1 & 3 & 13 \\
1 & 2 & 12 \\
2 & 2 & 11 \\
1 & 2 & 15 \\
2 & 2 & 12 \\
1 & 2 & 12 \\
3 & 2 & 14 \\
2 & 2 & 17 \\
1 & 2 & 12 \\
33 & 3 & 17 \\
1 & 3 & 17 \\
\hline 3 & 2 & 15 \\
2 & 2 & 17 \\
2 & 2 & 18 \\
1 & 3 & 14 \\
3 & 2 & 16 \\
3 & 3 & 16 \\
3 & 2 & 15
\end{tabular}

Depending on the degree to which participants endorsed the factor, it was rated as either '1 (white)', '2 (grey)' or '3 (black)'. If negatively associated with sustained weight loss, e.g. comfort eating, a high degree was given - the score 3 -, whereas 'moderate' or 'low' were given the scores 2 and 1, respectively. If positively associated with sustained weight loss, e.g. physical activity, a low degree was given the score 3, whereas 'moderate' or 'high' were given the score 2 and 1, respectively.

${ }^{a}$ The $\mathrm{p}$ value indicates the difference between weight reducers and regainers. A p value below 0.05 was considered significant.

The summated scores in table 3 show that there is an overlap of sum scores among successful weight reducers and regainers, as sum scores of 11,12, and 13 appear in both groups. This suggests that the factors and their interplays are not one-dimensional or linear but have a multidimensional hierarchical structure, which goes beyond simple summation. Thus, in the weight regainer group, combinations of e.g. affective and contextual factors appear to have prominence over behavioral factors as several low scores in behavioral factors 
(meal patterns, physical activity, and instrumental eating) are outweighed by high scores in just one affective factor (comfort eating) in combination with one high score in contextual factors (psychosocial stress).

\section{Discussion}

In summary, our findings suggest that successful weight maintenance is mediated by a complex multidimensional interplay between behavioral, affective, and contextual factors in which contextual factors seem to be of decisive importance. This is at odds with current behavior change models focusing on individual psychological resources [31,32] rather than on current life situation and challenges. Similarly, among behavioral factors, instrumentalization of eating appears to be the behavioral key factor. Low scores in instrumentalization outweighed all other behavioral factors. Although meal pattern was important, the factor was not decisive.

Thus; a main finding of this exploratory study is the identification of a new psychosocial factor in eating behavior which we have named 'instrumentalization of eating'. This concept encompasses the degree to which participants have made their eating behavior a tool to maintain weight loss. It comprises three dimensions: calorie counting, food choice based on nutrient content, and using monitoring tools (apps, schedules, or other). Most standard measures to map eating behavior mainly focus on factors that are cognitive or intentional. Hence, questionnaires elicit what patients aim at or wish for, but not necessarily what people actually do. To distinguish between cognitive aspects and practice, we have chosen to use the concept 'instrumentalization'. Instrumentalization is an ingrained practice that participants have implemented in their everyday life and only very rarely diverge from. It is thus systematic and repetitive. Instrumentalization describes a coherent set of practices that minimize choice and externalize control. As such, it might be explained not as cognitive, but behavioral restraint. For example in the TFEQ [12] item 32 is 'I count calories as a conscious means of controlling my weight'. Many patients may answer this item positively as it reflects their intentions, but nevertheless regularly lose control and consume more calories than their nutritional needs. In instrumentalization, calorie counting is turned into a pragmatic tool which rules practice, as when one participant states: 'I have a rule that each main meal must not contain more than 500 calories'. Item 32 thus addresses an abstract concern what patients intend, while instrumentalization constitutes a concrete, specified practice. From clinical work and weight management programs, practices such as calorie counting and scheduling meals are well-established as effective. It is common that patients strive to control their eating, but fail to do so. Nevertheless actual practices are seldom incorporated in questionnaires and other measures. Instrumentalization of eating thus constitutes an analytical category that captures a hitherto less explored aspect of food choice where eating becomes a tool to obtain a goal instead of a goal in itself. In contrast to concepts of restraint and abstain which describes how desires to eat are combatted, instrumentalization describes a positive strategy in which eating is re-defined as an activity with a strict aim: to (re)gain control of one's weight. The guiding principle is a regime of concrete practices, e.g. measuring portion sizes and scheduling meals, and it thus focuses on practices rather than on psychometric measures [12]. The instrumentalization regime draws extensively on nutritional discourse and logics, but its implementation departs from established nutrition education programs in that meal times, food items, and calorie content are not flexible but scheduled in a set routine. It differs from self-monitoring practices such as recording food intake in that eating behavior is fixed beforehand in order to reduce or eliminate choice in eating events and thereby avoid the risk of 'unhealthy choices' that might jeopardize successful weight maintenance. Instru- 
mental eating is thus enabled by a quantified system based on nutritional content of foods, which sets aside sensations of hunger or satiety, nor by cravings or palatability. Food choice and eating is transformed into a proactive instrumental practice, and not handled as the result of a biological drive that has to be controlled.

Further, we propose a multidimensional hierarchical structure model in which psychosocial and contextual factors are interrelated and constitute complex interplays, which designate specific combinations of factors as promoting or hampering weight loss maintenance [10]. Thus, the differences between weight reducers and regainers were not explained by single factors, such as level of nutritional knowledge or motivation, but by an accumulation of maladaptive behaviors and affective and contextual factors.

\section{Behavioral Factors}

Several eating behavior studies have demonstrated that meal timing and hunger management are strong predictors of weight loss and weight maintenance [33-35], and the decrease in hunger following a regular meal pattern has been identified as a significant predictor for weight loss [33]. In our study, weight reducers, compared to regainers, also reported a highly structured meal pattern, but, instrumentalization of eating emerged as even more important. Level of physical activity has been shown to be important for effective weight maintenance $[8,22]$. In our study, physical activity was not a significant factor. This may be explained by an implicit gender bias, i.e. men are more likely to use physical activity as a method to maintain weight while women (the majority in our study) change their diet [36, 37].

\section{Affective Factors}

Psychological analyses show that the degree of emotional eating such as comfort and reward eating are significant predictive variables for successful or unsuccessful weight maintenance and that eating in response to negative emotional states is associated with weight regain $[38,39]$. Correspondingly, in the present study weight reducers, compared to weight regainers, did not exhibit comfort eating. However, our data indicate that high degree of instrumentalization, even when combined with a moderate degree of reward eating, is helpful for sustained weight loss. Thus, an everyday pattern characterized by systematization and fixed rules, which guides food choice by nutritional content rather than hedonic value supplemented with controlled and limited treats on special occasions (see table 2 for citations), seems to be particularly advantageous. Elfhag and Rössner [8] similarly identified flexible restraint as a better predictor for weight loss maintenance than rigid cognitive restraint which is often characterized by a dichotomous 'all or nothing' approach to eating. This rigidity is associated with risk of breakdown of control and subsequent overeating, whereas flexible control which is characterized by a 'more or less' approach can be sustained in the long term $[8,32,40]$. Furthermore, moderate to high degrees of comfort eating seems to be an important affective factor and predictor of weight regain in our study.

\section{Contextual Factors}

High scores in contextual factors emerged as an important barrier to sustained weight loss, as reflected by a higher level of psychosocial stress in the weight regainer group. This is consistent with previous studies showing that high levels of psychosocial stress, lack of social support, and negative life events may provoke relapse and weight regain $[8,10]$. Our analysis suggests that, especially in combination with comfort and/or reward eating, psychosocial stress inhibit successful weight loss maintenance, while low degrees of psychosocial stress facilitate the sustained efforts that maintenance requires. Social support was not a significant factor for successful outcome. In general, contextual factors seem to influence the patients' 
ability to successfully change behavior and maintain such changes (see table 2 for citations). This finding is in line with the literature;. Thus, Phelan et al. [41] found a strong correlation between high levels of psychosocial stress and poor socioeconomic status and resources.

\section{Conclusions}

Our data suggest that the new concept 'instrumentalization' i.e. the degree to which participants have made their eating behavior an instrument to maintain weight loss, may be one of the predictors for sustained weight loss, especially when combined with a moderate degree of reward eating, a low level of psychosocial stress, and strong social support.

Larger trials should evaluate whether instrumentalization and the observed hierarchal structure and interplay of factors are general predictors of successful or unsuccessful weight loss maintenance. In future research, a standard quantitative measure of the concept should be developed, and its relation to existing standard psychometric measures should be systematically investigated.

\section{Acknowledgments}

The project was supported by funding from The Danish Diabetes Academy supported by The Novo Nordisk Foundation The Danish Research Counsel, Health and Disease (reference number: 11-107683), and the University Investment Capital (UNIK): Food, Fitness \& Pharma for Health and Disease from the Danish Ministry of Science, Technology and Innovation, the Lundbeck Foundation and The Novo Nordisk Foundation (grant number NNF160C00012345) and The P Carl Petersen Foundation. Cambridge Weight Plan products were donated from Cambridge Weight Plan. The funding sponsors were not involved in study design, conduction of the study, data analysis, or approval of manuscript. We thank the study participants, the dieticians Jane Hjort and Stine Larsen, Hvidovre Hospital.

\section{Funding}

Research relating to this manuscript was funded by the Danish Diabetes Academy supported by the Novo Nordisk Foundation, The Danish Research Council for Health and Disease and the University Investment Capital (UNIK): Food, Fitness \& Pharma for Health and Disease from the Danish Ministry of Science, Technology and Innovation. Cambridge Weight Plan products were donated from Cambridge Weight Plan.

\section{ClinicalTrials.gov Identifier}

NCT02094183.

\section{Disclosure Statement}

The authors have no relevant conflict of interest for this study. 


\section{References}

1 Boutayeb A, Boutayeb S, Boutayeb W: Multi-morbidity of non communicable diseases and equity in WHO Eastern Mediterranean countries. Int J Equity Health 2013;12:60.

2 Flegal KM, Kit BK, Orpana H, Graubard BI: Association of all-cause mortality with overweight and obesity using standard body mass index categories: a systematic review and meta-analysis. JAMA 2013;309:71-82.

3 Ayensa JI, Calderon MJ. Psychopathological comorbidity of obesity (in Spanish). An Sist Sanit Navar 2011;34: 253-261.

4 Seidell JC: Societal and personal costs of obesity. Exp Clin Endocrinol Diabetes 1998;106(suppl 2):7-9.

5 National Task Force on the Prevention and Treatment of Obesity, National Institutes of Health: Very lowcalorie diets. JAMA 1993;270:967-974.

6 Wing RR, Hill JO: Successful weight loss maintenance. Annu Rev Nutr 2001;21:323-341.

7 Wadden TA: Treatment of obesity by moderate and severe caloric restriction. Results of clinical research trials. Ann Intern Med 1993;119:688-693.

8 Elfhag K, Rössner S: Who succeeds in maintaining weight loss? A conceptual review of factors associated with weight loss maintenance and weight regain. Obes Rev 2005;6:67-85.

9 Klenk J, Rapp K, Ulmer H, Concin H, Nagel G: Changes of body mass index in relation to mortality: results of a cohort of 42,099 adults. PloS One 2014;9:e84817.

10 Hemmingsson E: A new model of the role of psychological and emotional distress in promoting obesity: conceptual review with implications for treatment and prevention. Obes Rev 2014;15:769-779.

11 Ogden J, Clementi C, Aylwin S: The impact of obesity surgery and the paradox of control: A qualitative study. Psychol Health 2006;21:273-293.

12 Stunkard AJ, Messick S: The three-factor eating questionnaire to measure dietary restraint, disinhibition and hunger. J Psychosom Res 1985;29:71-83.

13 Bandura A: Self-Efficacy. New York, Wiley and Sons, 1994.

14 Wallston KA, Wallston BS, DeVellis R: Development of the Multidimensional Health Locus of Control (MHLC) Scales. Health Educ Monogr 1978;6:160-170.

15 Epiphaniou E, Ogden J: Successful weight loss maintenance and a shift in identity: from restriction to a new liberated self. J Health Psychol 2010;15:887-896.

16 Sarlio-Lähteenkorva S: The battle is not over after weight loss: stories of successful weight loss maintenance. Health 2000;4:73-88.

17 Hillersdal L, Christensen BJ, Holm L: Patients' strategies for eating after gastric bypass surgery: a qualitative study. Eur J Clin Nutr 2016;70:523-537.

18 Iepsen EW, Lundgren J, Dirksen C, Jensen JE, Pedersen O, Hansen T, Madsbad S, Holst JJ, Torekov SS: Treatment with a GLP-1 receptor agonist diminishes the decrease in free plasma leptin during maintenance of weight loss. Int J Obes (Lond) 2015;39:834-841.

19 Chi MT: Quantifying qualitative analyses of verbal data: a practical guide. J Learning Sci 1997;6:271-315.

20 Riecke BF, Christensen R, Christensen P, Leeds AR, Boesen M, Lohmander LS, Astrup A, Bliddal H: Comparing two low-energy diets for the treatment of knee osteoarthritis symptoms in obese patients: a pragmatic randomized clinical trial. Osteoarthritis Cartilage 2010;18:746-754.

21 Britten N: Qualitative interviews in medical research. BMJ 1995;311:251-253.

22 Mozaffarian D, Hao T, Rimm EB, Willett WC, Hu FB: Changes in diet and lifestyle and long-term weight gain in women and men. N Engl J Med 2011;364:2392-2404.

23 Jeffery RW, Drewnowski A, Epstein LH, Stunkard AJ, Wilson GT, Wing RR, Hill DR: Long-term maintenance of weight loss: current status. Health Psychol 2000;19(1 suppl):5-16.

24 Jensen MD, Ryan DH, Apovian CM, Ard JD, Comuzzie AG, Donato KA, Hu FB, Hubbard VS, Jakicic JM, Kushner RF, Loria CM, Millen BE, Nonas CA, Pi-Sunyer FX, Stevens J, Stevens VJ, Wadden TA, Wolfe BM, Yanovski SZ, Jordan HS, Kendall KA, Lux LJ, Mentor-Marcel R, Morgan LC, Trisolini MG, Wnek J, Anderson JL, Halperin JL, Albert NM, Bozkurt B, Brindis RG, Curtis LH, DeMets D, Hochman JS, Kovacs RJ, Ohman EM, Pressler SJ, Sellke FW, Shen WK, Smith SC Jr, Tomaselli GF: 2013 AHA/ACC/TOS guideline for the management of overweight and obesity in adults: a report of the American College of Cardiology/American Heart Association Task Force on Practice Guidelines and The Obesity Society. Circulation 2014;129(25 suppl 2):S102-138.

25 Bruce Lawrence Berg HL: Qualitative Research Methods for the Social sciences. Boston, Pearson, 2004.

26 Strauss A, Corbin, J: Basics of Qualitative Research: Procedures and Techniques for Developing Grounded Theory. Los Angeles, Sage, 1998.

27 Wilby KJ, Govaerts MJ, Austin Z, Dolmans DH: Exploring the influence of cultural orientations on assessment of communication behaviours during patient-practitioner interactions. BMC Med Educ 2017;17, 61.

28 Guest G, Bunce A, Johnson L: How many interviews are enough? An experiment with data saturation and variability. Field Methods 2006;18:59-82.

29 Green J, Thorogood N: Qualitative Methods for Health Research, 3rd ed. London, Sage, 2013.

30 Wing RR, Phelan S: Long-term weight loss maintenance. Am J Clin Nutr 2005;82(1 suppl):222s-225s.

31 Prochaska JO, Velicer WF, Rossi JS, Goldstein MG, Marcus BH, Rakowski W, Fiore C, Harlow LL, Redding CA, Rosenbloom D, et al: Stages of change and decisional balance for 12 problem behaviors. Health Psychol 1994; 13:39-46. 
Christensen et al.: Instrumentalization of Eating Improves Weight Loss Maintenance in Obesity

32 Teixeira PJ, Silva MN, Coutinho SR, Palmeira AL, Mata J, Vieira PN, Carraca EV, Santos TC, Sardinha LB: Mediators of weight loss and weight loss maintenance in middle-aged women. Obesity (Silver Spring) 2010;18: 725-735.

33 Batra P, Das SK, Salinardi T, Robinson L, Saltzman E, Scott T, Pittas AG, Roberts SB: Eating behaviors as predictors of weight loss in a 6 month weight loss intervention. Obesity (Silver Spring) 2013;21:2256-2263.

34 Jakubowicz D, Froy 0, Wainstein J, Boaz M: Meal timing and composition influence ghrelin levels, appetite scores and weight loss maintenance in overweight and obese adults. Steroids 2012;77:323-331.

35 Marin-Guerrero AC, Gutierrez-Fisac JL, Guallar-Castillon P, Banegas JR, Rodriguez-Artalejo F: Eating behaviours and obesity in the adult population of Spain. Br J Nutr 2008;100:1142-1148.

36 Klem ML, Wing RR, McGuire MT, Seagle HM, Hill JO: A descriptive study of individuals successful at long-term maintenance of substantial weight loss. Am J Clin Nutr 1997;66:239-246.

37 Serdula MK, Mokdad AH, Williamson DF, Galuska DA, Mendlein JM, Heath GW: Prevalence of attempting weight loss and strategies for controlling weight. JAMA 1999;282:1353-1358.

38 Byrne S, Cooper Z, Fairburn C:. Weight maintenance and relapse in obesity: a qualitative study. Int J Obes Relat Metab Disord 2003;27:955-962.

39 Kayman S, Bruvold W, Stern JS: Maintenance and relapse after weight loss in women: behavioral aspects. Am J Clin Nutr 1990;52:800-807.

40 Westenhoefer J, Stunkard AJ, Pudel V: Validation of the flexible and rigid control dimensions of dietary restraint. Int J Eat Disord 1999;26:53-64.

41 Phelan JC, Link BG, Diez-Roux A, Kawachi I, Levin B: 'Fundamental causes' of social inequalities in mortality: a test of the theory. J Health Soc Behav 2004;45:265-285. 